\title{
ONTOLOGY-CENTERED INTEGRATION OF PROJECT MANAGEMENT, COST AND RESOURCE MODELING WITH ANALYSIS, SIMULATION AND VISUALIZATION: A CASE STUDY OF SPACE PORT OPERATIONS
}

\author{
Paul Fishwick \\ Zach Ezzel \\ Dept of Computer and Information Science and Engineering \\ College of Engineering \\ University of Florida \\ Bldg. CSE 301 PO Box 116120 \\ Gainesville, F.L. 32611, U.S.A.
}

\author{
Nabeel Yousef \\ David J. Miranda \\ Haluk Akin \\ Luis C. Rabelo \\ José Sepúlveda
}

\begin{abstract}
As the size and complexity of space launches continues to grow an architecture is becoming ever more necessary to accurately organize and determine workforce requirements for the involved organizations. The Launch Services Program at Kennedy Space Center has recently begun using a tool developed by the technology consulting firm Booz-Allen Hamilton specifically for this purpose. This paper addresses the possibility of transferring the information developed and organized by the Kennedy Workforce Planning Tool into a standard Microsoft Project document with integrated cost, resource modeling and analysis, simulation and visualization using an ontologycentered approach. The study emphasize on the potential of being able to forecast the workforce resource requirements.
\end{abstract}

\section{INTRODUCTION}

Space launches are increasingly complex projects that involve a large number of workforce requirements. To properly determine and accurately organize these requirements at Kennedy Space Center (KSC) the Launch Services Program (LSP) contracted Booz-Allen Hamilton to develop a tool that had the capabilities to accurately organize and determine workforce requirements for the space center. The result of this contract was the Kennedy Space Center Workforce Planning Tool. This tool exists in the Microsoft Excel environment and is automated through the use of Microsoft Visual Basic for Applications. For individual launches a standard Work Break- down Structure is used and the requirements for each are assigned for each month prior to launch. Unfortunately, the tool's complexity and its form of display output can not be considered user friendly. Cost and recourse planning were not included in the software. The software also lacks the capabilities of simulation or visualization.

Today, one of the most common project planning tools used in industry is Microsoft Project. This tool allows the user to plan a project with simple Gantt charts that allow the capability to assign resources to each task and identify task precedents. This paper addresses the possibility of transferring the information developed and organized by the Kennedy Workforce Planning Tool into a standard Microsoft Project document with integrated cost, resource modeling and analysis, simulation and visualization using an ontology-centered approach.

The study demonstrated the potential to predict workforce and resource requirements, do work breakdowns, and provide intensive visualization and human interaction. In addition, it has been proven that the integration of different types of cost modeling through a unique combination of human interaction (i.e., visual cross-hyperlinking) and knowledge modeling (i.e., ontology engineering) is possible. This creates tighter connections between software, hardware, and systems engineering. Two of the great benefits foreseen are 1) NASA Program/Project Managers can conduct "what-if" scenarios to immediately see the impact of a cost or schedule changes on procedures or the impact of a procedure change on cost and schedule; 2) NASA engineers can move Test \& Evaluation from the end of the Design, Development, Testing and Evaluation (DDT\&E) process to 
the front of the process while the design is still ongoing, saving time, money and resources, in particular for missions to the Moon and Mars.

Ontologies can support the vision of systems and applications integration. The notion of ontology as a formally specified conceptualization shared by a community of practice is now well established and is used and applied in several areas, including knowledge management, knowledge acquisition, information retrieval and extraction, knowledge engineering and knowledge modeling. Ontologies will be used to define and specify the main domain concepts for the framework developed in this research. The essential role of ontology is to support reuse and multi-dimensional mappings, which can take place in different scenarios. For instance ontologies have been used to support the specification of reusable libraries of problem solving components and simulation modeling (Miller et al. 2004, Fishwick and Miller 2004) to drive model-based knowledge acquisition, to allow semantic information retrieval and to structure collaborative decision-making processes by the automatic generation of multiple simulation models.

The launch chosen for the initial study was the Phoenix Mars Lander 2007 mission. The advantage of using this mission for the study was that it was a robotic mission that had many features in common with other launches at KSC. In the near future these results will be extended to allow KSC users to easily determine workforce requirements for other missions such as the Orion, Ares I, and Ares V configurations from the Constellation Program.

This paper focuses first on how the Workforce Planning Tool is used and some key information of what it provides to the user. Next, a general discussion of the Phoenix Mars Lander 2007 (Phoenix Mars Mission 2007) mission will be conducted. This will then be followed by a brief discussion of the study which attempts to transfer the information from the planning tool into Microsoft Project. As well as the development of ontologies for the creation of the frame-work used in future expansion.

\section{BACKGROUND}

\subsection{Kennedy Space Center Workforce Planning Tool Version 1.8b}

The Kennedy Space Center Workforce Planning Tool (KSC-WPT ) is a software tool designed to allow its users to determine total workforce requirements for individual organizations within the LSP. This tool was created by the technology consulting firm, Booz-Allen Hamilton under MOBIS Contract \# 19815-0054, D.O.\# 0013, KSC Order \# NNK04LA40D. The workforce requirements determined by this tool are established as a function of launch manifest related tasks. KSC-WPT also supports the identi- fication, over time, of the combined labor needs for KSC as well as for division and branch level planning. This tool uses the spreadsheet software program Microsoft Excel, automated through the use of Microsoft Visual Basic for Applications.

Currently, the tool holds launch manifests for 46 missions from KSC and Vandenberg Air Force Base (VAFB). The time period of this information ranges from the year 2005 to 2011. Based on any changes to these launch manifests the tool updates the workforce requirement templates of both space ports. The generation, changing, and presentation of these manifests is automated by a series of computations that are accessible in either tabular or graphical form. Through this tool the user is allowed to quickly run and compare multiple workforce demand templates for individual missions. These templates and sustaining demand are specified by individual Work Breakdown Structure items that can be edited and stored by the user.

The launch manifest template allows for three mission types to be inputted. These three types are: medium, small, and EELV. All three mission types allow the capability to launch the vehicles from KSC or VAFB. A medium type launch template uses the Delta II launch vehicle developed by Boeing. A small type launch uses the Pegasus, a winged space booster developed by Orbital Sciences. The EELV launch type uses the Atlas line of launch vehicle built by the Lockheed Martin Corporation.

The tool also allows the introduction of several standard workforce elements that are designated by their NASA division as well as their skill. Table 2 gives a list of the standard branch and skill subdivisions that can be inputted into the model.

Table 1: Basic Work Breakdown Structure (WBS) used in the KSC Workforce Planning Tool.

\begin{tabular}{cc}
\hline WBS Code & Task/ Sub-task \\
\hline 1.00 .0 & Mission Direct \\
1.01 .0 & Pre-Mission Planning \\
1.02 .0 & Mission Planning \\
1.03 .0 & Baseline and Procure \\
& Launch Services \\
1.04 .0 & Launch Site Integration and \\
& Test \\
1.05 .0 & Launch Vehicle Integration \\
1.06 .0 & Mission Integration / MRBs \\
& / VSTRs \\
1.07 .0 & Field Operations \\
1.08 .0 & Launch Campaign \\
1.09 .0 & Post Launch \\
2.00 .0 & Payload Carriers \\
3.00 .0 & Mission Adds \\
4.00 .0 & Indirect \\
5.00 .0 & Planning \\
\hline
\end{tabular}


Table 2: KSC Workforce Planning Tool Branch and Skill Codes (Ellis 2005)

\begin{tabular}{|c|c|}
\hline Skills & Names \\
\hline ELE & Electrical Systems Branch \\
\hline MAN & Mission Analysis Branch \\
\hline MEC & $\begin{array}{c}\text { Mechanical Systems } \\
\text { Branch }\end{array}$ \\
\hline RES & $\begin{array}{l}\text { Resident Offices (incl. } \\
\text { VBG) }\end{array}$ \\
\hline SEI & $\begin{array}{l}\text { Systems Engineering and } \\
\text { Integration }\end{array}$ \\
\hline CnT & $\begin{array}{l}\text { Communications \& Te- } \\
\text { lemetry Branch }\end{array}$ \\
\hline LIK & $\begin{array}{c}\text { Launch Site Integration } \\
\text { Kennedy }\end{array}$ \\
\hline MIM & $\begin{array}{l}\text { Mission Management Of- } \\
\text { fice }\end{array}$ \\
\hline PIO & Program Integration Office \\
\hline NLA & Nuclear Launch Approval \\
\hline LIV & $\begin{array}{c}\text { Launch Site Integration } \\
\text { Vandenberg }\end{array}$ \\
\hline LSI & $\begin{array}{l}\text { Launch Site Integration } \\
\text { Branch }\end{array}$ \\
\hline $\mathrm{PPO}$ & Program Planning Office \\
\hline RMO & $\begin{array}{l}\text { Resource Management Of- } \\
\text { fice }\end{array}$ \\
\hline OnP & Procurement Office \\
\hline VRO & $\begin{array}{l}\text { Vandenberg Resident Of- } \\
\text { fice }\end{array}$ \\
\hline SMA & $\begin{array}{l}\text { Safety \& Mission Assur- } \\
\text { ance Organization }\end{array}$ \\
\hline $\mathrm{ADM}$ & Administrative Office \\
\hline CFE & Chief Engineer \\
\hline OMA & Other Mission Analysis \\
\hline NLM & NASA Launch Manager \\
\hline EMC & Electromagnetic \\
\hline FCT & Flight Controls \\
\hline FSW & Flight Software \\
\hline FTD & Flight Design \\
\hline STD & Structural Dynamics \\
\hline STS & Stress \\
\hline THR & Thermal \\
\hline $\mathrm{COM}$ & Communications \\
\hline TEL & Telemetry \\
\hline STF & C\&T Mgt \& Staff \\
\hline
\end{tabular}

The configuration of the Work Breakdown Structure (WBS) follows a standard for all missions and it represents both mission-related demand and sustained demand across organizations within the model. The main structure used in this WBS is described in table 1.
This structure is not required to be followed and in fact most missions omit many of the tasks and subtasks from the general WBS.

\subsection{Phoenix Mars Lander 2007 Mission}

In August of 2007 the National Aeronautics and Space Administration (NASA) plans to launch the Phoenix Mars Mission aboard a Boeing Delta II rocket from the launch complexes at Cape Canaveral Air Force Station in Florida. The Phoenix will be the first mission in NASA's "Scout" program, an initiative for competitively proposed smaller, lower-cost spacecraft. These missions are intended to supplement the core mission of NASA's Mars Exploration Program. The Phoenix spacecraft (Figure 1) itself is modeled after a canceled NASA 2001 Lander, and is outfitted with instruments which are improved versions of the instruments that were carried onboard the failed 1999 Mars Polar Lander mission. The main objectives of the mission will be to study the history of water on the red planet and search for evidence of formerly habitable areas on the planet's artic regions. The Phoenix mission has three main leads in the form of the principal investigators at the University of Arizona, the project manager at the Jet Propulsion Laboratory (JPL), and the flight system manager at Lockheed Martin Space Systems.



Figure 1: Phoenix Mars Lander

(Source: http://phoenix.lpl.arizona.edu/ Date: 07/25/2006)

The Mission's Principal Investigator is Peter Smith of the University of Arizona's Lunar and Planetary Laboratory. The Principal Investigator is responsible for all aspects of the mission. Program management responsibility has been delegated to JPL under project manager Barry Goldstein. Mr. Goldstein will lead a team of experienced engineers and scientists who will conduct the functions of payload management, and flight systems and mission operations. JPL will also be in charge of interfacing the Phoenix vehicle with the Deep Space Network. This will send command sequences and receive data from the spacecraft. The team at JPL will maintain the vehicle on its proper trajectory all the way to its landing on the Martian surface. A science team will be led by Leslie Tamp- 
pari, a project scientist at JPL. The science team will have members with experience from all previous Mars robotic missions and expertise in the fields of atmospheric science, biology, chemistry, geology, and hydrology. The

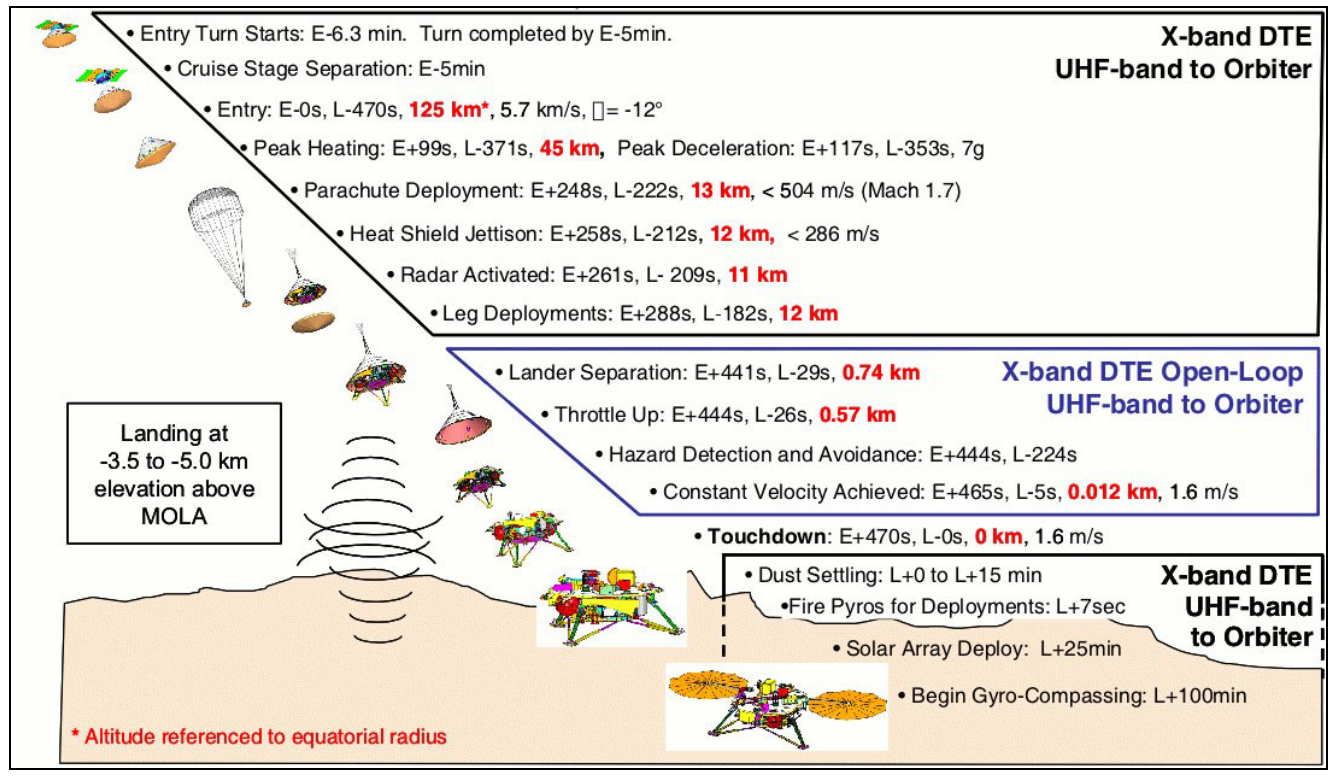

Figure 2: Summary of events of the vehicle's landing

(Source: http://phoenix.lpl.arizona.edu/ Date: 09/14/2006)

Lockheed Martin Space Systems team will be led by Ed Sedivy. This team will take the lead in the design, construction, and testing of the spacecraft. The Lockheed Martin team will also monitor the Phoenix's health throughout all phases of the mission (Phoenix Mars Mission 2007).

Unlike its recent predecessors the Phoenix will come to rest on Mars through the use of a controlled descent soft landing. The most recent Mars missions had used airbags to cushion their landings on the planet's surface. The soft landing method used by Phoenix was most recently attempted on the failed Mars Polar Lander mission in 1999 . The last successful landing of this type was the NASA Viking Mars missions of the 1970s. A summary of the events leading to the vehicle's landing can be seen in figure 2 .

According to the mission proposal the vehicle will also use the Lander structure, subsystem components, and the protective shell (Figure 3) which was originally constructed for a cancelled 2001 mission (Universe Today 2006). The recycling of these parts is hoped to save on expenses and allow the mission to stay within its budget of \$386 million (David 2006).

Upon its launch from Cape Canaveral Air Force Station it will begin a 10-month journey toward Mars. It is expected to land on the red planet in June of 2008 where it will begin operations on the planet's surface and begin its experiments. It is hoped that the information gained from this mission will assist the planning and develop- ment of NASA's manned Mars exploration program. Phoenix's successor in the Mars Scout line of missions will be decided in late 2007 with an expected launch in 2011 (Brown 2007).

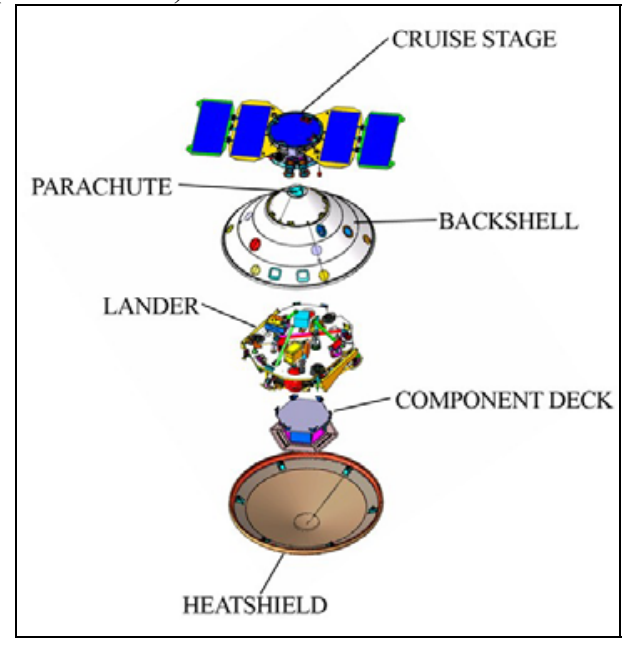

Figure 3: Expanded view of the Phoenix's cruise configuration (Source: http://phoenix.lpl.arizona.edu/ Date: $08 / 15 / 2006)$

\section{THE VIRTUAL TEST BED}

The group's experience in doing this type of research includes building a Virtual Test Bed (VTB) for NASA 
Ames at KSC (Rabelo et al. 2004, Park et al. 2005). The VTB is a collection (federation) of separate software processes and information modules that can coordinate and act as a single complex system. The VTB, which is based on the HLA and is used to model and simulate complex systems and behavior, is geared to integrate different simulations with legacy software as it executes a simulation run and can work with Java and non-Java based runtime infrastructures (RTIs).

The architecture provides a collaborative computing environment framework for fast modeling of high-tech enterprises and their ground processing through the use of reusable components and involves agent-based systems working in a distributed environment. It enables simultaneous access over the Internet, thus fostering a collaborative work environment. The group has demonstrated the VTB using computers running distributed federates of a new, expanded, federation at Ames, KSC, and UCF.

This innovative HLA-based infrastructure called the Virtual Test Bed was built over the last four years and in its present form integrates five federates:

1 A simulation - written in Arena by a team of researchers a few years back and still in use for operations analysis at KSC (Cates et al. 2002) of the Space Shuttle's process from landing to lift off and return

2 A weather expert system - written in Java in a Linux environment by a team of NASA Ames researchers (Rajkumar and Bardina 2003) — that determines in real time whether conditions are acceptable for launch

3 A launch control room simulation (AnyLogic, built with the help and mentoring of KSC personnel)

4 A MonteCarlo simulation (also in Arena) of the chances of a successful mission

5 An expectation of casualties (Ec) model (Rabelo et al. 2006a) that integrates: a geographical information system (ArcGIS), Calpuff (software that models gas dispersion), a data trajectory model (MathCad), a population model (LandScan), and a MonteCarlo model (Arena) to estimate the Ec that would result from a Space Shuttle accident within two minutes of lift off. The last two federates were built by the research team (Sepulveda et al. 2004, Rabelo et al. 2006b).

As indicated, some of the VTB federates are written in COTS software (Arena in particular) that is non-HLAcompliant software. The VTB's infrastructure includes software adapters that "fool" the RTI into believing that these federates are really HLA-compliant and make possible their interaction with other federates.

The VTB also has the ability to include federates written using Synchronous Parallel Environment for Emulation and Discrete-Event Simulation (SPEEDES), a software framework/toolbox for building parallel $\mathrm{C}++$ simulations, and person-in-the-loop and instrumentationin-the-loop capabilities. The VTB is working in room 205 of the Partnership 2 building at the University of Central Florida's Research Park and can be seen by anybody interested in the group's working implementation of distributed simulation.

The group is starting the design of an enhanced VTB from a solid experience and a proven product. By "enhanced" it is meant that the capabilities of the group's framework will be expanded by making it capable of interacting with agents - independent software entities that react to events and initiate actions on their own. Agents can be created and destroyed dynamically, move in space, communicate with each other, and have behavior, knowledge and goals. They can have different capabilities, roles, intentions, desires, beliefs, and some may be intelligent. The enhanced VTB may also include additional system dynamics simulation models to model the intricate behavior that characterizes planning procedures, execution policies, and exogenous market responses. In addition, the enhanced VTB will be able to interact with sensors (radar; discrete instrumentation such as temperatures, voltages, strains, vibrations), telemetry, and data collected from other instruments data collectors, live entities and autonomous agents, or passive viewers and other systems. It will also have access to real-time operational data (fully synchronous) and supply chain data (partially asynchronous) and will access enterprise software dealing with non-simulation situations (accounting, finance, human resources, inventory control, and production planning, scheduling, and supply chain information, among others).

\section{ONTOLOGIES}

The ontological centered approach will be able to map vehicle architectures and mission requirements to project management and from project management to resources, constraints, costs, visualizations, and simulation models. These simulation models will be executed in the Virtual Test Bed (VTB) and then provide different quantitative measures to guide the decision-making process.

In addition, the ontology centered integration will automatically generate simulation models which can be executed in the VTB using the multi-agents approach. This will allow for changes in the mission requirements that can be propagated using the ontology links to the simulation models and then be executed in the VTB to obtain the corresponding quantitative results for costs, lead times, throughput, and workforce requirements for space operations. Ontologies can be converted into XML code that can be read by Microsoft Project which shows the workforce planning through a Gantt chart. 


\section{VISUALIZATION AND A "HYPERLINK" ONTOLOGY ENVIRONMENT}

The group plans to take the developments on a task created involving the Space Shuttle and apply this toward the new NASA Constellation missions. The project to date focused on a task involving solid rocket booster (SRB) mating to the Shuttle. The reason for this focus is that the project management parameters are well known for Shuttle processing, and many digital media (including 3D models) are readily available for the shuttle.

The SRB mating process is defined organizationally through a Gantt chart, with task dependencies and resource allocations via MS Project.

This sub-task is explained as follows:

1. ET Transfer to VAB: Moving the External Tank to VAB. The ET arrives at KSC on a barge and is parked near the press site. The ET is then offloaded from a special trailer and towed to the VBA transfer isle where it is parked until it is integrated onto the stack (NASA Website 2007).

2. SRB Stacking at VAB_HB: The Solid Rocket Motor (SRB) stacking consists of placing an SRB aft skirt on to the Mobile Launch platform (MLP) which is parked in the High Bay (HB) of the VAB (The MLP is sitting on six pedestals. When it is ready to go to the pad, the pedestals are raised and the crawler pulls underneath. The pedestals are lowered and the MLP is secured to the crawler and transported to the pad at approximately $1 \mathrm{MPH}$ ).

3. ET Mate SRB in VAB: Mating the External tank with the Solid rocket booster.

4. Orbiter Time to VAB: The orbiter (Shuttle) is processed in the Orbital Processing Facility (OPF) which is close to the VAB. It is placed on a special trailer and towed to the $\mathrm{VAB}$ and placed in the $\mathrm{VAB}$ transfer isle. A strongback is attached to the orbiter and the vehicle is lifted up (almost to ceiling) and moved through an opening at the top, lowered and attached (mated with the ET and SRBs.)

5. ET SRB Orbiter Mating in VAB: The Orbiter is lifted and mated with ET+SRB.

A 3D visualization tool has been constructed, and is still undergoing further development, based on the open source OGRE 3D game engine. The tool has the following characteristics:

- The interface shows the graphical counterparts of all MS Project entities for that task

- All 3D models can be examined interactively, using zoom, unzoom
- All 3D models are fully selectable

- 3D animations of tasks are supported

- Media (sound, video, photographs, and web URLs are supported)

The tool is integrated with a plug-in written for MS project so that all elements of 1) MS Project and 2) the 3D tool are interconnected via user selection. This interaction is illustrated in Figure 4. This interaction is characterized as follows:

- Individual tasks selected in MS project will be shown in the 3D tool, along with resources and costs

- Multiple tasks or sub-tasks can also be selected in MS Project and the engineering aspects of these tasks are displayed in the 3D tool

- Region or point selected objects or 2D icons in the 3D tool will have corresponding elements and tasks in the MS Project window. These are highlighted

\section{CASE STUDY}

The main purpose of this study was to transfer the detailed workforce requirements from the Kennedy Workforce Planning Tool into a more user-friendly format such as a Gantt chart. To make this Gantt chart, Microsoft Project was chosen as the tool of choice as this software package can be considered a project planning standard.

Each mission detailed in the Workforce Planning Tool follows the generic WBS but depending on the mission some of these tasks are omitted, while others are inserted. The Mars Phoenix mission contains most of the subtasks of task 1.00.00 (Mission Direct), but tasks 2.00.00 (Payload Carriers), 4.00.00 (Indirect), and 5.00.00 (Planning) are completely omitted and task 3.00.00 (Mission Adds) only has subtask 3.03.00 (Vehicle Competition and Award) included under it.

Overall, the final Microsoft Project document consisted of 2 main tasks (Mission Direct and Mission Adds) and 9 main subtasks (Pre-Mission Planning, Mission Planning, Baseline \& Procure Launch Services, Launch Site Integration, Launch Vehicle Integration, Vehicle Process Build, Field Operations, Launch, Post Launch, and Vehicle Competition and Award).

Under the main tasks and subtasks there were a total of 127 tasks. Some of these 127 tasks were unique to the mission and are not part of the standard tool WBS structure. Also, some separate tasks were given the same WBS code. For example, the Mission Planning subtask (1.02) 




Figure 4: Two way interaction between MS Project and the 3D tool

had 51 tasks under it with 45 different tasks all given the same WBS code 1.02.00. Also, some resources were given the same task twice, but with contradictory time allocations. An example of this problem can be found in the Post Launch subtask (1.09.00) in which the resource VED-STS is allocated to work in the time period from $9 / 3$ to $10 / 31$ and then also from $8 / 1$ to $9 / 28$.

One of the main drawbacks of using the information derived from the Workforce Planning Tool was that it did not identify predecessors for each task and so unfortunately the Microsoft Project document would also be unable to display such information. As a result, no critical path on the network diagram could be determined.

To accurately transfer the information that the Workforce Planning tool outputted into a Microsoft Project document several changes needed to be made. These changes included the presentation of resource utilizations, resource descriptions, and time representations.

One of the first changes that needed to be made was how resource utilizations were displayed. In the Workforce Planning Tool resource utilizations are displayed in units of Full Time Equivalents (FTEs). An FTE is a NASA standard that is based off a percentage of an employee's time. For example, if a NASA employee is scheduled to spend $50 \%$ of his/her time on a NASA project then the project will be paying 0.50 FTEs for that employee. What this also implies is that 1 FTE equals 40 hours of work for each week in one month. When this information was inputted into Microsoft Project the FTEs were translated into hours.

The method in which resources were described in the Workforce Planning Tool also needed to be changed when this information was transferred into Microsoft Project. The tool displayed each task as assigned to a resource, and each resource was described by its division and skill. When transferring this information into Microsoft Project it was decided to simplify this by combining division and skill into one category entitled DivisionSkill. The reason a separate designation was used in the Workforce Planning Tool was because other tabs in the tool could display the entire resource utilization of each division and each skill separately. In the case of the Microsoft Project document this was not necessary because what was of interest was the utilization of each type of resource. Overall there were 34 Division-Skill resource types included in the Project document.

Another change that needed to be made was in how time is displayed. The Workforce Planning Tool displays time as a countdown based on the scheduled launch date. In other words, months are displayed as L minus (or plus) however many months are between this date and the launch date. Microsoft Project on the other hand, displays the passage of time in time units such as days, weeks, months, quarters, and years. When transferring this information to Microsoft Project it was decided to convert the L minus/plus dates into the actual month and year it refers to. So for example, in the case of Mars Phoenix, a date of L-93 in the Workforce Planning Tool is converted to November 1999 in the Microsoft Project document. The Workforce Planning Tool displayed information up to 96 months prior to launch, the launch month, and then 3 months after launch for a total of 100 months.

The ontology-centered integration approach can help NASA model and assess the foremost problems associated with the exploration of space. NASA needs to learn how to disentangle the relative influence of the different factors and to assess the implications for spaceport operations. The conversion of a mission plan into a Gantt chart form can also be accomplished using Ontologies. This conversion is done as follows: First, the requirements and 
the resources for the mission are acquired. Then, all this information is put into the ontology created protégé OWL. This way the information is made to be sure in the standard form. Once the ontology is in the knowledgebase then it's translated into an xml file which complies with MS Project XML schema. MS Project reads from this file and automatically creates the MS Project file which can create the Gantt chart (See figure 5).

At this point, a translator is being worked on which can use the same XML file to create a simulation of the mission. Decision makers will be able to change the simulation by solely changing the requirements and resources of the mission. Lacy and Gerber also show the potential uses of ontologies in simulation modeling in their work (Lacy and Gerber 2004).

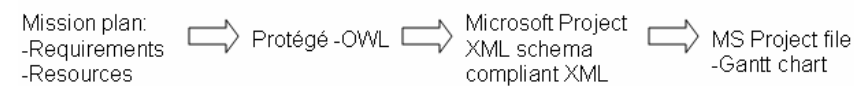

Figure 5: Conversion from mission plan to the Gantt chart

\section{CONCLUSION}

In this paper, it was shown that it is possible to transfer the workforce knowledge inside the KSC Workforce Planning Tool into a more user friendly format such as Microsoft Project. Unfortunately, there are still some gaps that need to be resolved for a complete and accurate picture of workforce requirements at the center. These include a complete understanding of precedents, a standardization of WBS elements and codes, as well as the automatic correction of resource utilization contradictions. Once these issues can be resolved it is hoped that this case study can assist in the development of a simulation tool that will allow KSC users to easily determine workforce requirements for launches at the center.

The group is expected to deliver an ontologycentered integration approach, a system for the interactive mapping of mission objectives and vehicle architectures to requirements, from requirements to project management, and from project management to visualization, resources, costs and simulations capable of running in the enhanced Virtual Test Bed to provide quantitative results to measure performance. This platform will integrate different dimensions of the NASA Operations Enterprise.

\section{ACKNOWLEDGEMENTS}

We wish to thank the people at NASA Kennedy Space Center, especially Mr. Jeppie Compton, for the great help and support they have provided us.

\section{REFERENCES}

Brown, D. 2007. NASA Selects Proposals for Future Mars Missions and Studies. Available via $<$ http://www.nasa.gov/home/hqnews/2007/jan/HQ_0 7003_Mars_missions.html $>$ [accessed February 5, 2007].

Cates, G.R., M.J. Steele, M. Mollaghasemi, G. Rabadi. 2002. Modeling The Space Shuttle. Proceedings of the 2002 Winter Simulation Conference, E. Yucesan, C.-H. Chen, J.L. Snowdon, and J.M. Charnes, eds.

David, L. 2006. Detailed Look at the Next Mars Lander. $<$ http://www.space.com/businesstechnology/061206_ mars_lander.html $>$ [accessed February 5, 2007].

Ellis, E. 2005. Kennedy Space Center Workforce Planning Tool Version 1.8b User's Guide \& Technical Manual. Booz Allen Hamilton, Virginia

Fishwick, P.A. and J.A. Miller. 2004. Ontologies for Modeling and Simulation: Issues and Approaches. Proceedings of the 2004 Winter Simulation Conference, R .G. Ingalls, M. D. Rossetti, J. S. Smith, and B. A. Peters, eds.

Lacy, L. and W. Gerber. 2004. Potential Modeling and Simulation Applications of the Web Ontology Language - OWL. Proceedings of the 2004 Winter Simulation Conference, R .G. Ingalls, M. D. Rossetti, J. S. Smith, and B. A. Peters, eds.

Miller, J.A., G.T. Baramidze, A.P. Sheth, P.A. Fishwick. 2004. Investigating Ontologies for Simulation Modeling. Proceedings of the $200437^{\text {th }}$ Annual Simulation Symposium.

NASA web site. 2007. Available via < http://science.ksc.nasa.gov/facilities/vab.html > [accessed February 5, 2007].

Park, J., R. Moraga, L. Rabelo, J. Dawson, M. Marin, and J. Sepulveda. 2005. Addressing Complexity Using Distributed Simulation: A Case Study in Spaceport Modeling. Proceedings of the 2005 Winter Simulation Conference, M. E. Kuhl, N. M. Steiger, F. B. Armstrong, and J. A. Joines, eds.

Phoenix Mars Mission 2007. Uncovering the Mysteries of the Martian Arctic. Available via $<$ http://phoenix.lpl.arizona.edu/mission.php $>\quad$ [accessed February 5, 2007].

Rabelo, L., J. Sepulveda, M. Marin, and J. Park. 2004. A Distributed Environment for Spaceports. SAE 2004 Transactions, Journal of Aerospace. Vol. 113, 15071515.

Rabelo, L., J. Sepulveda, J. Compton, R. Moraga, and R. Turner, 2006a. Disaster and Prevention Management for the NASA Shuttle during Lift-Off. Disaster and Prevention Management Journal. Vol.15, No. 2, pp. 262-274.

Rabelo, L., J. Sepulveda, J. Compton, and R. Turner. 2006b. Simulation of Range Safety for the NASA 
Space Shuttle. Aircraft Engineering \& Aerospace Technology: An International Journal. Vol. 78, 2, 98106

Rajkumar, T. and J.E. Bardina. 2003. Web-based weather expert system (WES) for Space Shuttle launch. 2003. IEEE International Conference on Systems, Man and Cybernetics.,

Sepulveda, J., L. Rabelo, and J. Compton. 2004. A Distributed Environment for Analysis of Events Related to Range Safety. SAE 2004 Transactions, Journal of Aerospace, Vol. 113, No. 1, 1516-1521.

Universe Today 2006. Phoenix Mars Lander is Coming Together. Available via $<$ http://www.universetoday.com/am/publish/phoenix _mars_2007.html?252006> [accessed February 5, 2007].

\section{AUTHOR BIOGRAPHIES}

PAUL FISHWICK Paul A. Fishwick is Professor of Computer and Information Science and Engineering at the University of Florida. He received the $\mathrm{PhD}$ in Computer and Information Science from the University of Pennsylvania, and his research areas are complex systems, modeling methodology and simulation. He is a Fellow of the Society for Computer Simulation and served as General Chair of the 2000 Winter Simulation Conference. He currently serves on several simulation-related editorial boards including ACM Transactions on Modeling and Computer Simulation and the Transactions of the Society for Modeling and Simulation International. His e-mail address is: <fishwick@cise.ufl.edu>

ZACH EZZEL received his Bachelors in Digital Arts and Sciences Engineering from the University of Florida in 2006. $\mathrm{He}$ is currently studying towards his $\mathrm{PhD}$ in Computer Engineering with a specialty in Computer Graphics and Modeling. His e-mail address is: < zezzell@cise.ufl.edu>

NABEEL YOUSEF is an assistant professor in the Engineering Technology Department at the University of Central Florida, Orlando. He is the Director of IT and Infrastructure for NSF Center for e-Design at University of Central Florida. Director of the IEMS conference since 2002. He has experience RTI/HLA, Simulation and Modeling Analysis, System and Cost Integration, and Information Technology. He had his MS in Simulation and Modeling at the University of Central Florida. He received the First Simulation Scholarship fall 2002. . He holds a B.S. in Physics and Computer Science from Jordan. His email address is <nyousef@mail.ucf.edu>.

DAVID J. MIRANDA received his Bachelors in Aerospace Engineering from the University of Central Florida.
$\mathrm{He}$ is currently pursuing a Masters in Industrial Engineering and a Masters in Business Administration at the University of Central Florida. His e-mail address is: $<$ djmiranda@mail.ucf.edu>.

HALUK AKIN is studying towards his Ph.D degree at the Industrial Engineering and Management Systems Department at the University of Central Florida where he received his M.S. degree in 2004. He received his B.S. degree from Yildiz Technical University, Istanbul in 2002. His e-mail address is <halukakin@gmail.com>.

LUIS RABELO, Ph.D., is an Associate Professor in the Department of Industrial Engineering and Management Systems at the University of Central Florida. He received dual degrees in Electrical and Mechanical Engineering from the Technological University of Panama and Master degrees from the Florida Institute of Technology and the University of Missouri-Rolla. He received a Ph.D. in Engineering Management from the University of MissouriRolla in 1990 where he also did Post-Doctoral work in Nuclear Engineering. He also holds dual MS degrees in Aerospace Systems Engineering \& Management from the Massachusetts Institute of Technology. He has over 240 publications and three international patents. His e-mail address is <lrabelo@mail.ucf.edu>.

JOSÉ A. SEPÚLVEDA, Ph.D., P.E., is an Associate Professor in the Department of Industrial Engineering and Management Systems at the University of Central Florida. He received an Ingeniero Civil Químico degree from the Universidad Santa María, Valparaíso, Chile, and MSIE, $\mathrm{MPH}$, and Ph.D. (Industrial Engineering) degrees from the University of Pittsburgh. Dr. Sepúlveda's major areas of research interest are object-oriented simulation, simulation optimization, risk analysis, catastrophe response, measuring and modeling training effectiveness, tasks scheduling in complex and risky environments, and applications of industrial engineering and simulation in health care. His e-mail address is <sepulved@mail.ucf.edu>. 